\title{
Design and management of business models and processes in services science
}

\author{
Yves Pigneur · Hannes Werthner
}

Published online: 26 February 2008

(C) Springer-Verlag 2008

Information technology has changed the way, how companies perform business, how they develop services and interact with customers as well as other companies. This is accompanied by an ongoing virtualization of the economy, think of the "value" of companies like Google, ebay, or Skype. Their value is based on information and their "user network", not on the physical infrastructure or products. In this context, paralleled by the growth of the so-called service industry (or sector), one can observe an "informatisation" of work, value chains, products as well as services. The term "service" point at a close interaction of supplier and customer with the simultaneity of production and consumption. It refers to an exchange between supplier and consumer for the provision of (intangible) assets.

The all-embracing utilization of IT following its principles of transparency enables new forms of networked organization, referring to the concept of smart business networks. The focus is on flexible service design, implementation and delivery, putting the customer at the center. The underlying issue is to link strategy, business models, business processes and implementation (utilizing service oriented architectures) for flexible design, implementation and adaptation. To fully exploit its potential, research in this domain must focus on these factors, and on the applicability of the corresponding technologies.

It is important to note that the term service has to be seen from different points of view, from management science, information systems and computer science. These different views also refer to the important distinction between service, e-service and

\footnotetext{
Y. Pigneur $(\bowtie)$

Institute of Information Systems, University of Lausanne,

1015 Lausanne, Switzerland

e-mail: yves.pigneur@unil.ch

H. Werthner

Institute for Software Technology and Interactive Systems, Vienna University of Technology, 1040 Vienna, Austria

e-mail: hannes.werthner@ec.tuwien.ac.at
} 
web service. And whereas on the technical level one can observe an increasing maturity and acceptance of web services and service-oriented architectures (SOA) by both industry and academia, on the business level the landscape is still rather heterogeneous. Consequently, this special issue focuses on the latter, on the design and modeling of services on the business level, on strategy, business models and business process models.

This issue contains a set of six papers, where we have selected from 18 submitted contributions. Please note that this issue is part of a series of special issues of the journal Information Systems and e-Business Management on topics related to the emerging and multidisciplinary field of Services Science. The first article, by Dorn et al., "From Business to Software: A B2B Survey" can be seen as a kind of an introduction paper. In their work - taking the Open-edi reference model as a basethey classify the rather huge number of different approaches and specifications targeting co-operations in the e-commerce (B2B) domain. They differentiate between the business layer-covering business models and business process models - and the technical layer. In the latter the focus is clearly on service-oriented architectures (SOA). Thus, they concentrate on the business layer, where-in contrast to the technical layer-the landscape is still very diverse. This is not astonishing since on this layer the respective approaches follow different point of views. In addition, the authors propose-on a conceptual level-to integrate business modeling with process modeling in order to make the transformation from business services to web services more transparent. They envision that-on the long run-this process of linking business models and business process models could be (semi)automated.

The two following articles, i.e., "Aligning Goals and Services through Goal and Business Modelling" by Andersson et al., and "Strategic Reasoning about Business Models: A Conceptual Modeling Approach" by Samavi et al., focus on the linkage between strategy and business models. Thus, they both consider also the WHY (strategy) and not only the WHAT (business model) dimension of doing business. Andersson et al. present an approach that utilizes goal and business models as the foundation for designing services. The approach can be used to ensure that the developed e-services support the desired goals and business values of involved actors. In this context goal models are used to capture and to make explicit the goals of a business enterprise. They direct the enterprise toward concrete actions, and as a consequence, the actions are firmly based on a business justification.

Samavi et al. state that strategic reasoning about business models is an integral part of service design. In their paper they define a strategic modeling framework to help understand and analyze the goals, intentions, roles, and the rationale behind the strategic actions in a business environment. They state that this understanding is necessary in order to improve existing or design new services. Their key component of their approach is a strategic business model ontology for representing and analyzing business models and strategies. This firmly based ontology introduces a strategy layer which reasons about alternative strategies that are realized in the operational layer. Both papers use case studies to evaluate their approaches.

The third article "Quality Management in Service Ecosystems" by Riedl et al. treats the important topic of quality management in what they call service 
ecosystems. They define such a system, more precisely a Web Service Ecosystem, as a logical collection of web services whose exposure and access are subject to constraints characteristic of business service delivery. Starting with the observation that SOA and web services mature and have become widely accepted and used by industry, users start to re-combine and to mediate other providers' services in ways that have not been anticipated by their original provider. Within organizations and cross-organizational communities, discoverable services are organized in repositories providing convenient access to adaptable end-to-end business processes. In this context the issue is how quality management can be performed. Service quality management is a key challenge when services are composed of a dynamic set of heterogeneous sub-services from different service providers. Their paper contributes to this important area by developing a reference model of quality management in service ecosystems.

Rouached et al. develop "A Semantical Framework To Engineering WSBPEL Processes". In enterprise application integration web service composition is of interest, referring to the process of combining web services to provide value-added services. WSBPEL as an industry standard offers the notation and control mechanisms for the execution of business processes in web service collaborations. But WSBPEL does not provide support for checking interesting properties related to web service and process behavior. Attempting to fill this gap, the authors describe a formalization of WSBPEL business processes that adds communications semantics to the specifications of interacting web services, and uses a formal logic to model their dynamic behavior. This also enables their formal analysis and the inference of relevant properties of the systems being constructed. The process of behavior analysis moves from a single local process to that of modeling and analyzing the behavior of multiple processes across different composition domains.

The final paper by Birgit Hofreiter, named "Extending UN/CEFACT's Modeling Methodology by a UML Profile for Local Choreographies", focuses on UMM (UN/ CEFACTs Modeling Methodology). UMM is a UML profile for specifying global choreographies of inter-organizational e-business systems, where, however, the practical use of UMM is limited to bi-lateral business collaborations. It does not support nested business transactions. In consequence, UMM does not support multiparty business collaborations. To close this gap the paper introduces an approach to extend UMM to local, multi-party choreographies.

We want to thank all the authors who have submitted papers, the many reviewers for their valuable input and comments, and the editors of the journal who have invited us to prepare and to organize this special issue. We think that- thanks to all of them-this special issue of Information Systems and e-Business Management represents a valuable contribution to the emerging field of Services Science. 